\title{
High efficiency decolorization of azo dye Reactive Black 5 by Ca-Al
}

\section{particles}

Wael Ben Mbarek ${ }^{1}$, Eloi Pineda ${ }^{2, *}$, Lluïsa Escoda ${ }^{3}$, Joan J. Suñol ${ }^{3}$ and Mohamed Khitouni ${ }^{1}$

${ }^{1}$ Laboratoire de Chimie Inorganique, Faculté des Sciences, Universitéde Sfax, Ur-11-Es-73, Tunisie.

${ }^{2}$ Departament de Física, Universitat Politècnica de Catalunya - BarcelonaTech, ESAB, 08660

Castelldefels, Spain

${ }^{3}$ Departament de Física, Universitat de Girona, Campus Montilivi, 17071 Girona, Spain

*Corresponding author: Joan J. Suñol. E-mail: joanjosep.sunyol@udg.edu

\begin{abstract}
This work studies the degradation of azo dye Reactive Black 5 by Ca-Al metallic particles prepared by melt-spinning and ball-milling. The morphology and the phase structure of the metallic powders were characterized and the decolorization efficiency of Reactive Black 5 solutions were assessed by monitoring the dye degradation by ultraviolet-visible absorption spectrophotometry. The decolorization process using the $\mathrm{Ca}-\mathrm{Al}$ powders showed fast kinetics and high efficiency. $40 \mathrm{mg} \mathrm{L}^{-1}$ dye solution was successfully decolorized in 1 min using $0.1 \mathrm{~g} / 100 \mathrm{~mL}$ of $\mathrm{Ca}_{65} \mathrm{Al}_{35}$ powder, suggesting it as an effective, low-cost means for degradation of azo-compounds.
\end{abstract}

Keywords: Ball milling; Rapid solidification; Reactive Black 5; Decolorization. 


\section{Introduction}

Wastewater from textile industry is still a major water-treatment challenge in many countries[1,2]. New dyes are designed to better resist degradation of the color; thus demanding a continuous effort in research for developing new, cheaper and more efficient processes for wastewater treatment. One of the biggest family of textile dyes used nowadays is the so-called azo-dyes, which are characterized by the presence of one or more azo-bounds $(-\mathrm{N}=\mathrm{N}-)$ acting as chromophores of the molecule. Many different chemical and biological approaches are employed for the removal of azo dyes [3]. Decolorization by solid particles is one of such methods, in which synthetic dyes are adsorbed onto a solid surface or degraded by a reaction generated by the material. Metal oxides, polymers, zeolites and zero-valent metals $(Z \mathrm{VM})$ are promising materials because of rapid decolorization reactions and convenient operation in practical applications [4-6]. The use of solid materials facilitates the confinement of the particles during the treatment and, after the process, their removal can be easily done by simple physical separation methods.

In the case of metallic particles, the specific area and chemical properties of their surface are of crucial importance. The degradation reaction involves a redox process in which surface metal atoms lose electrons to cleave the bonds of the organic molecules $[7,8]$. For instance, the use of zero-valent iron (ZVI) particles is a well-known strategy applied to degradation of many different compounds [7,9]. Some recent advances have been focusing on improving the particles efficiency by means of two approaches. The first approach is the increase of specific surface area that can be achieved by the production of nano-sized particles of different types of metals $[10,11]$. The second approach is the production of micro-sized flakes or powders of metastable amorphous or nanocrystalline metallic phases in order to increase the reaction activity of the metals. Metallic metastable phases can be produced by rapid solidification techniques [12-14] thus increasing the efficiency of the decolorization process [15-17]. 
Large differences depending on the powder production method have been reported, with ball milled particles showing the highest reaction activity [16]. In particular, high-energy mechanical milling process was used to prepare fine powders with high surface area. Indeed, the high density of microstrain and lattice defects and the intrinsic brittleness of these milled powders facilitates their subdivision into fine particles. However, knowledge of the effect of milling conditions on microstructural and catalytic properties of alloys remains limited. Recently, a a mechanically alloyed binary Mn-Al system [18] showed the modification of the catalytic properties favoured by composition and a decolorization efficiency of about $100 \%$. One of the elements was found more reactive in the reduction process in aqueous media. These interesting results promoted us to explore the Ca-Al system, as a low-cost, new adsorbent for the removal of azo-dyes. As the redox potentials arre $-2,76$ and 1,18 for $\mathrm{Ca}$ and $\mathrm{Mn} 2+/ \mathrm{Mn}$ respectively $\mathrm{Ca} \mathrm{s}$ chosen here as a substitute for the $\mathrm{Mn}$ in order to observe whether this factor favors dye degradation.

The degradation of the azo dye Reactive Black 5 (RB5) has been studied by several methods [19-21], being used as a representative compound to assess the efficiency of decolorization methods of azo-dyes. In this work we report the production method of $\mathrm{Ca}_{65} \mathrm{Al}_{35}$ particles prepared by melt-spinning and subsequent ball-milling, and their potential as a catalyst material to degrade RB5 aqueous solutions.

\section{Experimental procedure}

Alloy ingots of $\mathrm{Ca}_{65} \mathrm{Al}_{35}$ (at\%) were prepared by arc melting (MAM1 Edmund Bühler device) using pure $\mathrm{Ca}(99.9 \mathrm{wt} \%)$ and $\mathrm{Al}(99.99 \mathrm{wt} \%)$ under a Ti- gettered argon atmosphere. The ingots were melted by induction (Melt Spinner SC Edmund Bühler device) and injected through a $0.8 \mathrm{~mm}$ nozzle on a spinning copper wheel obtaining rapidly quenched ribbons with a thickness of $40 \mu \mathrm{m}$. The ribbon (flakes) samples were then put into a high energy planetary ball mill (Fritsch pulverisette 7) with a rotation speed of $600 \mathrm{rpm}$. Both the 5 balls 
with $12 \mathrm{~mm}$ diameter and the vial are made of tempered chromium steel. The balls to ribbons weight ratio was 5:4. The ribbon flakes were introduced and milled under argon atmosphere to avoid oxidation process. A time of 5 min waiting interval was applied after each $10 \mathrm{~min}$ to avoid sample heating and powder agglomeration. The total milling time was 3 hours.

The morphology and structure of the Ca-Al powder were examined using a scanning electron microscope $(\mathrm{SEM})$ equipped with a $\mathrm{Vega}^{\circledR}$ Tescan energy dispersive X-ray (EDX) analyzer andan X-ray diffraction (XRD) on a Siemens D500 using $\mathrm{CuK}_{\alpha}$ radiation. The size distribution of the particles was obtained from the SEM images by Image J software analysis, erode and despeckle algorithms were applied to isolate the particle images from the background and the remaining touching particles were removed manually prior to the calculation of the size distribution. The crystalline structure and crystallographic parameters of the Ca-Al alloys were estimated through the Rietveld refinement of XRD patterns using the MAUD program based on the Rietveld method. The specific surface area of the Ca-Al powder was determined using the $\mathrm{N}_{2}$ adsorption/desorption analysis according to the Brunauer-Emmett-Teller (BET) conducted at $77 \mathrm{~K}$ on a Nova $4200 \mathrm{e}$ model surface area analyzer (Quantachrome Instrument Corporation).

Aqueous solutions of RB5 with concentrations of $40 \mathrm{mg} \mathrm{L}^{-1}$ were used to evaluate the decolorization reaction. Degradation experiments were performed with $0.01,0.05$ and $0.1 \mathrm{~g}$ of ball milled (BM) powders added into $100 \mathrm{~mL}$ of the dye solution and continuously agitated. Samples were drawn out at regular time intervals and centrifuged at $3000 \mathrm{rpm}$ for 15 min in a Rotanta 460r centrifuge. The supernatants were separated and the absorbance between 200 and $800 \mathrm{~nm}$ was measured by spectrophotometry (Shimadzu $2600 \mathrm{UV}$-visible). The powder collected after degradation was analyzed using Fourier transform infrared spectroscopy (FTIR) spectrum to determine the presence of functional groups in the extract. The pellets were prepared in each case with the same quantity of ground sample in $\mathrm{KBr}$ and 
the spectra were normalized for comparison between different samples. Semi quantitative elemental composition was analyzed by EDX.

The degradation process of RB5 and the qualitative analysis of the aromatic by-products were investigated by high performance liquid chromatography (HPLC) coupled with tandem mass spectrometry (LC-MS/MS). The HPLC analyses were carried out using a Beckman Gold chromatograph fitted with a Proshell 120 Pheny Hexyl $(4.6$ x 150 mm x $2.7 \mu \mathrm{m})$ column at room temperature. The determination of the extent of dye abatement was conducted isocratically with the detector selector at $\lambda=597 \mathrm{~nm}$ using a 90:10 (v/v) aqueous solution of ammonium acetate/methanol mixture as the mobile phase. A flow rate of $0.5 \mathrm{~cm}^{3}$ $\min ^{-1}$ and injection volume of $0.2 \mathrm{~cm}^{3}$ was always used.

\section{Results and discussion}

Figure $1(\mathrm{a}, \mathrm{b})$ shows the micrographs of the $\mathrm{Ca}_{65} \mathrm{Al}_{35}$ as-produced powders. The particles surface is characterized by flows and corrugations; a closer inspection reveals that larger particles are aggregations of roundish finer particles. The production method is therefore able to generate a large surface area. Figure 1c shows the size-distributions calculated from the SEM images. The mean particle size, $d$, and the standard deviation , $\sigma$, of the distribution of the as-produced powders are $d=16.3 \mu \mathrm{m}$ and $\sigma=6.6 \mu \mathrm{m}$. The EDX analysis shown in Figure 1d confirmed that the expected elemental composition of $\mathrm{Ca}$ and $\mathrm{Al}$ was approximately equals to $65: 35$.

Figure $2(a, b)$ shows the UV-Vis spectrum evolution of dye aqueous solutions for different particle-weight/solution-volume ratios $(0.01,0.05$, and $0.1 \mathrm{~g} / 100 \mathrm{~mL})$ of $\mathrm{Ca}_{65} \mathrm{Al}_{35}$ particles. Before the treatment the maximum of absorbance located at $\lambda_{\max }=597 \mathrm{~nm}$ in the visible region arises from the $-\mathrm{N}=\mathrm{N}$ - azo bond. The decolorization process is extremely fast in all cases, although it saturates if the amount of added particles is less than $0.05 \mathrm{~g} / 100 \mathrm{~mL}$. The UV-Vis spectrum evolution of dye aqueous solutions after the addition of $0.1 \mathrm{~g} / 100 \mathrm{~mL}$ 
of $\mathrm{Ca}-\mathrm{Al}$ particles reveals a fast and complete decolorization as shown in Figure 2c. The absorbance at $597 \mathrm{~nm}$ decays into nearly zero after $1 \mathrm{~min}$ and the solution becomes fully transparent. The other two peaks at 230 and $310 \mathrm{~nm}$ are ascribed to the benzene and naphthalene rings of the dye [7]. The changes in the absorbance reflect the evolution of the RB5 chromophores, the peak at $\lambda_{\max }$ becomes weaker, indicating cleavage of the azo bonds, formation of $-\mathrm{NH}_{2}$ groups and decomposition of $\mathrm{RB} 5$. This is confirmed by the rapid increase of the peak at $246 \mathrm{~nm}$. These results are in agreement with those observed by Zhang et al. [19] using amorphous zero-valent iron and Ben Mbarek et al.[18] using Mn-Al particles as decolorizing material for RB5 aqueous solutions. Figure $2 \mathrm{~d}$ presents the images of RB5 solutions before and after being processed.

The evolution of the decolorization efficiency (\%) during the process was calculated using Eq. 1 as follows:

$\left(C_{0}-C_{t}\right) / C_{0} \times 100$

where $C_{t}$ is the dye concentration at time $t$ and $C_{0}$ the initial concentration. The effect of $\mathrm{Ca}_{65} \mathrm{Al}_{35}$ particles dosage on RB5 removal was investigated in the range $0.01-0.1 \mathrm{~g} / 100 \mathrm{~mL}$ keeping constant the temperature $\left(25^{\circ} \mathrm{C}\right)$ and the initial dye concentration $\left(40 \mathrm{mg} \mathrm{L}^{-1}\right)$. Figure 3 shows that by increasing the $\mathrm{Ca}-\mathrm{Al}$ dosage from 0.01 to $0.1 \mathrm{~g} / 100 \mathrm{~mL}$, the dye removal percentage increased from $25 \%$ to $100 \%$. In addition, more calcium content is available for oxidation and hence, more hydrogen is produced to hydrogenate the azo bonds of RB5.

A survey of the results found in literature show that the decolorization of azo dyes by ZVI is much less efficient and slower [5], even when aided by reduction of $\mathrm{pH}$, increase of temperature, photo-oxidation or other complementary treatments [8]. Rahmani et al. [20] obtained a reaction time of $t=30 \mathrm{~min}$ and final decolorization $60 \%$ using $0.3 \mathrm{~g} / 150 \mathrm{~mL}$ of ZVI particles in $50 \mathrm{mg} \mathrm{L}^{-1} \mathrm{RB} 5$ aqueous solution. Chompuchan et al. [21] reported $k^{-1}>100$ min when adding $0.25 \mathrm{~g} / 100 \mathrm{~mL}$ of nanoscale ZVI in $100 \mathrm{mg} \mathrm{L}^{-1} \mathrm{RB} 5$ solution. Considering 
the initial dye concentration and the quantity of powder per volume, the decolorization process observed for $\mathrm{Ca}_{65} \mathrm{Al}_{35}$ is more efficient and rapid than any other reported in the cited works.

Figure $4(a, b)$ shows the surface morphology of the ball milled powder after the reaction. After the degradation process the surface become smooth and flower-like products cover the whole surface compactly. Similar morphologies were found covering the surface after the reaction in Fe-based [16], $\mathrm{Mg}_{73} \mathrm{Zn}_{21.5} \mathrm{Ca} 5.5$ [17] and $\mathrm{Mg}_{65} \mathrm{Cu}_{25} \mathrm{Y}_{10}$ [22] metallic glass particles or ribbons. After the reaction, the size distributions of the $\mathrm{Ca}_{65} \mathrm{Al}_{35}$ alloy (Figure 4c) shifted towards higher values, $d=31.9 \mu \mathrm{m}$ and $\sigma=11.7 \mu \mathrm{m}$, due to the effect of the precipitates growing on the particles surface. The EDX analysis shown in Figure 4d indicates the ratio of $\mathrm{Ca}$ to $\mathrm{Al}$ and $\mathrm{O}$ was approximately equal to $34.3: 16.8: 49.0$. The intense peak for oxygen confirming that the needle-like products consist of crystalline oxide and hydroxide precipitates.

One important factor linked to reactivity is the specific surface area. To understand the high reaction efficiency of the $\mathrm{Ca}-\mathrm{Al}$ powder, the specific surface area was measured by the Brunauer-Emmett-Teller (BET) method. The specific surface area measured was $15.16 \pm 0.31$ $\mathrm{m}^{2} \mathrm{~g}^{-1}$. This value makes Ca-Al powder promising candidates for degradation of azo dyes by comparison with typical values ranging between 0.343 to $16.62 \mathrm{~m}^{2} \mathrm{~g}^{-1}$ given in the literature $[16-18,22,23]$. Thus, mechanical alloying also improves the specific surface area of the powder mixture due to the introduction of corrugations or porous-like structures at the nanoscale. The high surface area provides abundant active sites for the adsorption and degradation of RB5 dye.

Likewise, microstructure (nanocrystalline size and density of defects) can also improve the reactivity [18]. The phase structures of all the Ca-Al samples before and after degradation reaction were evaluated by XRD technique. Figure 5a shows the XRD patterns of the melt- 
spinned ribbons and figure 5 (b) of the as-produced powders after the ball-milling process. The $\mathrm{Ca}_{65} \mathrm{Al}_{35}$ ribbons show the characteristic amorphous halo, with weak crystalline peaks that could not be attributed to any known $\mathrm{Ca}-\mathrm{Al}$ intermetallic phase in equilibrium according to the phase diagram Al-Ca. Different batches of ribbons showed different degree of amorphicity, indicating that the glass-forming ability of this composition is very low. Few prominent crystalline reflections can be observed in the XRD spectrum of the as-produced powder; therefore, the energy introduced by the ball-milling process triggers the crystallization of the metallic glass. This crystalline phase is obtained through devitrification during the milling process. The XRD patterns of the ribbons milled for $3 \mathrm{~h}$ revealed the presence of one metastable tetragonal Ca-Al phase with $a=b=3.0929 \pm 0.0004 \AA$, $c=8.2472 \pm 0.0006 \AA$ lattice parameters. Furthermore, the inner-particle crystalline size is nanometric, $49 \pm 2 \mathrm{~nm}$, and the microstrain is $1.5 \pm 0.1 \%$. Thence, the high-energy mechanical treatment can considerably improve the reactivity of the alloy by achieving a high specific surface area coupled with a nanocrystalline structure with the consequent high level of grain boundaries, microstrain and crystallographic defects.

Figure 5c also shows the XRD patterns of the powders after the decolorization process. New crystalline reflections appear in addition to the ones associated to the metastable $\mathrm{Ca}-\mathrm{Al}$ phase, which come from the hydroxides covering the particles surface as it was clearly suggested by microanalysis. These reflections can be identified as a $\mathrm{Ca}(\mathrm{OH})_{2}$ phase with space group $\mathrm{P}-3 \mathrm{~m} 1$ and $\mathrm{Al}(\mathrm{OH})_{3}$ phase with space group P-21/a.

Figure 6a shows the FT-IR spectrum of RB5 dye powder before decolorization. In this figure we can see peaks at $3500-3700 \mathrm{~cm}^{-1}$ (-NH stretch), $2888-2968 \mathrm{~cm}^{-1}\left(\mathrm{CH}_{2}\right), 1626-$ $1748 \mathrm{~cm}^{-1}$ (C = $\mathrm{C}$ stretch), $1387-1635 \mathrm{~cm}^{-1}\left(\mathrm{~N}-\mathrm{H}\right.$ bending), $1078-1256 \mathrm{~cm}^{-1}\left(\mathrm{O} \_\mathrm{C}\right)$, the band around $1145 \mathrm{~cm}^{-1}$ could be sulphonic groups $\left(-\mathrm{SO}_{3}\right)$, and finally at $1011-1078 \mathrm{~cm}^{-1}$ (alkenes). The most representative peak of azo dye is about $1495 \mathrm{~cm}^{-1}$ which corresponds (N 
$=\mathrm{N}$ stretch). FTIR spectrum of the residual organics products on the surface of $\mathrm{Ca}_{65} \mathrm{Al}_{35}$ powder after degradation process is shown in figure 6b. Comparatively, the peak of $-\mathrm{NH}$ stretch is increased and the peak at $3000-3500 \mathrm{~cm}^{-1}$ is more pronounced and broad because of $\mathrm{O} \_\mathrm{H}$ stretch. The vibration range from 2750 to $3000 \mathrm{~cm}^{-1}$ (possible $\mathrm{C}-\mathrm{H}$ stretch aliphatic) disappeared. The peaks from 800 to $1500 \mathrm{~cm}^{-1}$ decreased and the appearance of new peaks around $1400 \mathrm{~cm}^{-1}\left(\mathrm{C} \_\mathrm{C}\right.$ Aryl) and at $850 \mathrm{~cm}^{-1}\left(\mathrm{C} \_\mathrm{N}\right.$ Aryl) are observed. The peak at $1495 \mathrm{~cm}^{-1}(\mathrm{~N}=\mathrm{N}$ stretch) is gone after the degradation process. Summarizing, the peaks observed after degradation were for $\mathrm{N}-\mathrm{H}, \mathrm{O}-\mathrm{H}, \mathrm{C}-\mathrm{H}, \mathrm{C}-\mathrm{C}$ and $\mathrm{C}-\mathrm{N}$ clearly indicating the formation of primary amines as a result of the reductive cleavage of the azo bond $(-\mathrm{N}=\mathrm{N}-)$ and confirming the above mentioned UV-Vis results (see Figure 2). Similar results have been obtained by Yang et al. [24] studying the decolorization ability of zerovalent iron (ZVI) as well as Ben Mbarek et al. [18] and Mendez et al. [25] studying the degradation of the RB5 solution using BM Mn-Al alloys and nickel electrodes in divided and undivided cells, respectively.

Degradation of the RB5 dye was further confirmed by HPCL. Figure 7a shows the chromatogram of the dye in solution before degradation with a broad peak eluting at 2.9 min and Figure $7 \mathrm{~b}$ shows the mass spectrum of the same peak. The mass spectrum complexity comes from the hydrolysis of sulphated azo dye (RB5, M.W=903). The information on the structures was obtained from the detected negative ions in the spectrum: $[\mathrm{M}-2 \mathrm{H}+\mathrm{Na}]^{-},[\mathrm{M}-$ $\left.2 \mathrm{H}-\mathrm{SO}_{3}+\mathrm{Na}\right]^{-},\left[\mathrm{M}-\mathrm{H}-\mathrm{SO}_{3}\right]^{-},\left[\mathrm{M}-2 \mathrm{H}-\mathrm{SO}_{3}\right]^{-},\left[\mathrm{M}-\mathrm{H}-\mathrm{SO}_{3}-\mathrm{H}_{2} \mathrm{SO}_{4}\right]^{-},\left[\mathrm{M}-\mathrm{H}-2 \mathrm{H}_{2} \mathrm{SO}_{4}\right]^{-},\left[\mathrm{M}-\mathrm{H}-\mathrm{SO}_{2}-\right.$ $\left.\mathrm{SO}_{3}-\mathrm{H}_{2} \mathrm{SO}_{4}\right]^{-},\left[\mathrm{M}-3 \mathrm{H}-\mathrm{SO}_{3}+\mathrm{Na}\right]^{-}$and more monovalent ions from the hydrolysis process and divalent ions [26]. Figure 8a represents the HPLC elution profile of RB5 reacted with Ca-Al alloy for $20 \mathrm{~min}$. It can be seen that instead of the peak of the parent dye a new peak was found eluting at $2.7 \mathrm{~min}$, thereby suggesting the transformation of the dye. Figure $8 \mathrm{~b}$ shows the mass spectrum of the product peak eluting at $2.7 \mathrm{~min}$. The peaks could be ascribed to 
aromatic amines end products as 1-2-7-triamino-8-hydroxy-3-6-naphthalinedisulphonate (MW=349), 1-sulphonic,2-(4-aminobenzenesulphonyl)-ethanol $\quad(\mathrm{M} . \mathrm{W} .=281) \quad$ and $\quad 1-$ sulphonic,2-(4-hidroxibenzenesulphonyl)-ethanol (M.W.=282) and also to derivative products as a consequence of substitution or interaction reactions with the aqueous medium.

The appearance of bubbles inside the solution suggests the formation of hydrogen gas as a direct reaction product of the redox process. Based on this fact, the mechanism of the dye degradation proposed is driven by the release of $\mathrm{H}_{2}$ from the reduction of water, the posterior cleavage of $-\mathrm{N}=\mathrm{N}-$ bonds and, finally, the formation of $-\mathrm{NH}_{2}$ groups. The enrichment in $\mathrm{OH}^{-}$ ions as result of the reduction process of water leads to an increase of the $\mathrm{pH}$ value in the dye solution. According to the measurement, the $\mathrm{pH}$ value increases from initial 6.3 to about 9.8 after the degradation by the $\mathrm{Ca}-\mathrm{Al}$ powder. In these $\mathrm{pH}$ conditions, precipitate of calcium hydroxide is formed and the passivation of aluminum takes place. However, the initial reactivity of calcium to form calcium ions, $\mathrm{Ca}^{2+}$, leads the process of formation of hydrogen gas and the subsequent hydrogenation and rupture of the azo groups. The existence of the aluminum corrosion was assumed from oxygen detected by EDX (Fig 4) and the formation of $\mathrm{Al}(\mathrm{OH})_{3}$ and $\mathrm{Ca}(\mathrm{OH})_{2}$ by XRD analysis (Fig. 5).

The reduction reactions caused by zero-valent metallic particles are characterized by a reaction rate proportional to the surface area [7]. Here, a reduction of the amount of particles (less initial calcium available on the surface of the alloy) results in a decrease of the final decolorization but the kinetics remains always extremely fast. This indicates the process is related to the reactivity in water of intermetallic phases forming the $\mathrm{Ca}-\mathrm{Al}$ powders, producing the degradation of the dye molecule at the same time that covers the particles surface with calcium hydroxide precipitates. The final decolorization efficiency is then limited by the surface area but the reaction rate is controlled by the high chemical activity in water. 
The reactivity of metals in environmental remediation applications is attributed to the porosity of the oxide layers formed in contact with the aqueous medium. For instance, the long term activity of ZVI is basically due to the non-protective oxide scales formed during iron corrosion [27]. In other words, the remediation ability of metallic particles is favored if corrosion is persistent and can progress through the bulk material. Pure aluminum particles do not show remediation ability, as it is well-known that aluminum generates a homogeneous protective alumina layer [28]. However, in the case of Mn-Al particles Ben Mbarek et al. [18] proposed that the colorant degradation reaction was driven by the initial release of electrons by both $\mathrm{Al}$ and $\mathrm{Mn}$ atoms. In that article, the oxidation process of the $\mathrm{Mn}$ atoms and their subsequent dissolution in the aqueous medium caused pitting on the exposed aluminum oxide film favoring the subsequent oxidation process. A similar mechanism is expected in Ca-Al particles, the progressive dissolution of the $\mathrm{Ca}$ ions in the water generates pitting in the surface of aluminum oxide favoring the corrosion process. It suggests that both $\mathrm{Al}$ and $\mathrm{Ca}$ are contributing to the degradation reaction. Both hydroxide are very insoluble and precipitate in the surface of $\mathrm{Ca}_{65} \mathrm{Al}_{35}$ particles. The mechanism can be written as:

$$
\begin{aligned}
& \mathrm{Ca} \rightarrow \mathrm{Ca}^{2+}+2 e^{-} \\
& \mathrm{Al} \rightarrow \mathrm{Al}^{3+}+3 e^{-} \\
& 2 \mathrm{H}_{2} \mathrm{O}+2 e^{-} \rightarrow 2 \mathrm{OH}^{-}+\mathrm{H}_{2} \\
& \mathrm{Ca}^{2+}+2 \mathrm{OH}^{-} \longrightarrow \mathrm{Ca}(\mathrm{OH})_{2} \\
& \mathrm{Al}^{3+}+3 \mathrm{OH}{ }^{-} \longrightarrow \mathrm{Al}(\mathrm{OH})_{3} \\
& \mathrm{R}-\mathrm{N}=\mathrm{N}-\mathrm{R}^{\prime}+\mathrm{H}_{2} \longrightarrow \mathrm{R}-\mathrm{NH}-\mathrm{NH}-\mathrm{R}^{\prime} \\
& \mathrm{R}-\mathrm{NH}-\mathrm{NH}-\mathrm{R}^{\prime}+\mathrm{H}_{2} \longrightarrow \mathrm{R}-\mathrm{NH}_{2}+\mathrm{R}^{\prime}-\mathrm{NH}_{2}
\end{aligned}
$$

The reductive character of both $\mathrm{Ca}$ and $\mathrm{Al}$ and the instantaneous release of hydrogen gas bubbles justify the proposed mechanism described in equations 2, 3 and 4 . The formation of hydroxyl ions from water is manifested by the increase in $\mathrm{pH}$ above 7 (initial $\mathrm{pH} 5.6$ ), 
although this $\mathrm{pH}$ could be attributed to the presence of amino groups. However, the formation of insoluble calcium and aluminum hydroxides (eq. 5 and 6) is corroborated by SEM micrographs (flower-like products on the surface), by the results of EDX (oxygen content, figure 4), as well as by the XRD results (formation of hydroxides, Figure 5) or FT-IR (with an increase of the peak between 3000-35000 $\mathrm{cm}^{-1}$ ) typical of the $\mathrm{O} \_\mathrm{H}$ bond (Figure 6).

The results obtained in this work indicate that the $\mathrm{Ca}-\mathrm{Al}$ powders are efficient reducing agents like RB5, in neutral $\mathrm{pH}$ conditions this material is more suitable than other materials for the degradation of RB5 solution. This has a practical significance because there would be no need to add any acid into the actual industrial textile wastewater before the treatment. A schematic view of the proposed degradation mechanism of RB5 using Ca-Al system is given in figure 9.

The decolorization process using $\mathrm{Ca}-\mathrm{Al} \mathrm{BM}$ powders show, basically, the same advantages as other metallic particles; easy application and easy particle removal by simple physical separation methods. Furthermore, $\mathrm{Ca}_{65} \mathrm{Al}_{35}$ particles have low cost, relatively simple preparation and they are expected to be completely harmless both for health and environment.

\section{Conclusions}

Ca65 $\mathrm{Al}_{35}$ powders were successfully fabricated by melt spinning and ulterior ball milling. Its efficiency to degrade organic chemicals was investigated by evaluating the decolorization process of RB5 aqueous solutions. The ball milled powder exhibited excellent degradation efficiency and high reaction rates: Dye removal of more than $90 \%$ of $40 \mathrm{mg} \mathrm{L}^{-1}$ dye solutions in less than one minute. This high efficiency is associated to the large surface area and the particles chemical activity, which suggests these materials may be used as a low-cost, highperformance decolorizing method for textile wastewater pre-treatments. A chemical 
mechanism in aqueous basic medium is proposed, the mechanism is based on the reducing power of $\mathrm{Ca}$.

\section{Acknowledgements}

Work funded by MINECO grant FIS2014-54734-P and Generalitat de Catalunya grant 2014SGR00581. Financial support from MPCUdG2016/045 project is also acknowledged.

\section{References}

[1] N.K. Amin, Removal of direct blue-106 dye from aqueous solution using new activated carbons developed from pomegranate peel: Adsorption equilibrium and kinetics, J. Hazard. Mater. 165 (2009) 52-62. doi:10.1016/j.jhazmat.2008.09.067.

[2] T. Yahagi, M. Degawa, Y. Seino, T. Matsushima, M. Nagao, T. Sugimura, Y. Hashimoto, Mutagenicity of carcinogenic azo dyes and their derivatives, Cancer Lett. 1 (1975) 91-96. doi:10.1016/S0304-3835(75)95563-9.

[3] S.T. Ong, P.S. Keng, W.N. Lee, S.T. Ha, Y.T. Hung, Dye Waste Treatment, Water. 3 (2011) 157-176. doi:10.3390/w3010157.

[4] D.A. Fungaro, L.C. Grosche, A. Pinheiro, J. de C. Izidoro, S.I. Borrely, Adsorption of methylene blue from aqueous solution on zeolitic material for color and toxicity removal, Orbital- The Electronic Journal of Chemistry 2 (2011) 235-247. doi:10.17807/orbital.v2i3.129.

[5] S. Nam, P.G. Tratnyek, Reduction of azo dyes with zero-valent iron, Water Res. 34 (2000) 1837-1845. doi:10.1016/S0043-1354(99)00331-0.

[6] M. Ramesh, H.S. Nagaraja, M.P. Rao, S. Anandan, N.M. Huang, Fabrication, characterization and catalytic activity of $\alpha-\mathrm{MnO} 2$ nanowires for dye degradation of reactive black 5, Mater. Lett. 172 (2016) 85-89. doi:10.1016/j.matlet.2016.02.076.

[7] J. Cao, L. Wei, Q. Huang, L. Wang, S. Han, Reducing degradation of azo dye by zerovalent iron in aqueous solution, Chemosphere. 38 (1999) 565-571. doi:10.1016/S0045-6535(98)00201-X.

[8] W. Feng, D. Nansheng, H. Helin, Degradation mechanism of azo dye C. I. reactive red 2 by iron powder reduction and photooxidation in aqueous solutions, Chemosphere. 41 (2000) 1233-1238. doi:10.1016/S0045-6535(99)00538-X.

[9] N. Ruiz, S. Seal, D. Reinhart, Surface chemical reactivity in selected zero-valent iron samples used in groundwater remediation, J. Hazard. Mater. 80 (2000) 107-117. doi:10.1016/S0304-3894(00)00281-8.

[10] J. Fan, Y. Guo, J. Wang, M. Fan, Rapid decolorization of azo dye methyl orange in aqueous solution by nanoscale zerovalent iron particles, J. Hazard. Mater. 166 (2009) 904-910. doi:10.1016/j.jhazmat.2008.11.091.

[11] S. Bhakya, S. Muthukrishnan, M. Sukumaran, M. Muthukumar, T. Senthil Kumar, M. Rao, Catalytic Degradation of Organic Dyes using Synthesized Silver Nanoparticles: 
A Green Approach, J. Bioremediation Biodegrad. $6 \quad$ (2015) 1000312. doi:10.4172/2155-6199.1000312.

[12] B. Feuerbacher, Phase Formation in Metastable Solidification of Metals, Mater. Sci. Reports 4 (1989) 1-40, doi:10.1016/S0920-2307(89)80008-8.

[13] H. Liebermann, Manufacture of amorphous alloy ribbons, IEEE Trans. Magn. 15 (1979) 1393-1397. doi:10.1109/TMAG.1979.1060429.

[14] J. Duszczyk, P. Jongenburger, Properties of Particles Produced by Different Rapid Solidification Techniques, Powder Metall. 29 (1986) 20-26. doi:10.1179/pom.1986.29.1.20.

[15] C. Zhang, H. Zhang, M. Lv, Z. Hu, Decolorization of azo dye solution by Fe-Mo-SiB amorphous alloy, J. Non. Cryst. Solids. 356 (2010) 1703-1706. doi:10.1016/j.jnoncrysol.2010.06.019.

[16] J.-Q. Wang, Y.-H. Liu, M.-W. Chen, G.-Q. Xie, D. V. Louzguine-Luzgin, A. Inoue, J.H. Perepezko, Rapid Degradation of Azo Dye by Fe-Based Metallic Glass Powder, Adv. Funct. Mater. 22 (2012) 2567-2570. doi:10.1002/adfm.201103015.

[17] J.-Q. Wang, Y.-H. Liu, M.-W. Chen, D. V Louzguine-Luzgin, A. Inoue, J.H. Perepezko, Excellent capability in degrading azo dyes by $\mathrm{MgZn}$-based metallic glass powders, Sci. Rep. 2 (2012) 418. doi:10.1038/srep00418.

[18] W. Ben Mbarek, M. Azabou, E. Pineda, N. Fiol, L. Escoda, J.J. Suñol, M. Khitouni, Rapid degradation of azo-dye using Mn-Al powders produced by ball-milling, RSC Adv. 7 (2017). doi:10.1039/c6ra28578c.

[19] C.Q. Zhang, Z.W. Zhu, H.F. Zhang, Z.Q. Hu, Rapid decolorization of Acid Orange II aqueous solution by amorphous zero-valent iron, J. Environ. Sci. 24 (2012) 10211026. doi:10.1016/S1001-0742(11)60894-2.

[20] A. R. Rahmani, M. Zarrabi, M.R. Samarghandi, A. Afkhami, H.R. Ghaffari, Degradation of Azo Dye Reactive Black 5 and Acid Orange 7 by Fenton-Like Mechanism, Iran. J. Chem. Eng. 7 (2010) 87-94.

[21] C. Chompuchan, T. Satapanajaru, P. Suntornchot, P. Pengthamkeerati, Decolorization of Reactive Black 5 and Reactive Red 198 using Nanoscale Zerovalent Iron, Int. J. Chem. Mol. Nucl. Mater. Metall. Eng. 3 (2009) 7-11.

[22] X. Luo, R. Li, J. Zong, Y. Zhang, H. Li, T. Zhang, Enhanced degradation of azo dye by nanoporous-copper-decorated $\mathrm{Mg}-\mathrm{Cu}-\mathrm{Y}$ metallic glass powder through dealloying pretreatment, Appl. Surf. Sci. 305 (2014) 314-320. doi:10.1016/j.apsusc.2014.03.069.

[23] Y. Tang, Y. Shao, . Chen, X. Liu, S. Q. Chen and K. F. Yao, Insight into the high reactivity of commercial $\mathrm{Fe}-\mathrm{Si}$-B amorphous zero-valent iron in degrading azo dye solution, RSC advances, 3 (2015) 34032. doi:10.1039/c5ra02870a.

[24] Y.Y. Yang, Z.L. Li, G. Wang, X.P. Zhao, D.E. Crowley, Y.H. Zhao, Computational Identification and Analysis of the Key Biosorbent Characteristics for the Biosorption Process of Reactive Black 5 onto Fungal Biomass, PLoS One. 7 (2012) e33551. doi:10.1371/journal.pone.0033551.

[25] A. J. Mendez-Martinez, M. M. Davila-Jimenez, O. Ornelas-Davila, M. P. ElizaldeGonzalez, U. Arroyo-Abad, I. Sirès, E. Brillas, Electrochemical reduction and oxidation pathways for reactive Black5 dye using nickel electrodes in divided and undivided cells, 59 (2012) 140-149. doi:10.1016/j.electacta.2011.10.047. 
[26] D. Vanerková, A. Sakalis, M. Holpacek, P. Jandera, A. Voulgaropoulos. Analysis of electrochemical degradation products of sulphonated azo dyes using high-performance liquid chromatography/tandem mass spectrometry, Raid. Commun. Mass Spectrom. 20:19 (2006) 2807-2015.

[27] C. Noubactep, Elemental metals for environmental remediation: Learning from cementation process, J. Hazard. Mater. 181 (2010) 1170-1174. doi:10.1016/j.jhazmat.2010.05.085.

[28] L. Zhang, X. Gao, Z. Zhang, M. Zhang, Y. Cheng, J. Su, A Doping Lattice of Aluminum and Copper with Accelerated Electron Transfer Process and Enhanced Reductive Degradation Performance, Sci. Rep. $6 \quad$ (2016) 31797. doi:10.1038/srep31797. 


\section{Figure Captions}

Figure 1.(a and b) Particles morphology of the of $\mathrm{Ca}_{65} \mathrm{Al}_{35}$ particles before the decolorization process.(c) Distribution of particle sizes of the ball milled powders.(d) The nominal compositions as examined by EDX.

Figure 2.(a-c) The changes of UV absorption spectra along with the treatment Ca65 $\mathrm{Al}_{35}$ particles at $25^{\circ} \mathrm{C}$ for different dosage of powder.(d) Image of black 5 solutions processed by $\mathrm{Ca}_{65} \mathrm{Al}_{35}$ powder before and after degradation times up to $20 \mathrm{~min}$.

Figure 3. Kinetics of decolorization of RB5 dyed water using different particleweight/solution-volume ratios of $\mathrm{BM} \mathrm{Ca}_{65} \mathrm{Al}_{35}$ powder: $0.01 \mathrm{~g} / 100 \mathrm{~mL}, 0.05 \mathrm{~g} / \mathrm{mL}$ and $0.1 \mathrm{~g} / 100 \mathrm{~mL}$ of particles in $40 \mathrm{mg} \mathrm{L}^{-1} \mathrm{RB} 5$ aqueous solution.

Figure 4. $(\mathrm{a}$ and $\mathrm{b})$ Particle morphologies of the of $\mathrm{Ca}_{65} \mathrm{Al}_{35}$ particles after the decolorization process. (c) Distribution of particle sizes of the ball milled powders. (d) Nominal compositions as examined by EDX.

Figure 5. (a) XRD patterns of the $\mathrm{Ca}_{65} \mathrm{Al}_{35}$ ribbons. (b) XRD patterns of the ribbon milled before and (c) after the degradation of RB5.

Figure 6. (a) FTIR spectra of RB5 powder before degradation reaction and (b) FTIR spectra of $\mathrm{Ca}_{65} \mathrm{Al}_{35}$ powder after degradation of RB5. 
Figure 7.(a) HPLC elution profile of the native RB5 dye and (b) mass spectra of the peak from 2.9 min at $\lambda=597 \mathrm{~nm}$.

Figure 8. (a) HPLC elution profiles after degradation of the RB5 dye and (b) mass spectra of peaks from $2.7 \mathrm{~min}$.

Figure 9. A schematic view of the proposed degradation mechanism of RB5 using $\mathrm{Ca}_{65} \mathrm{Al}_{35}$ compound. 

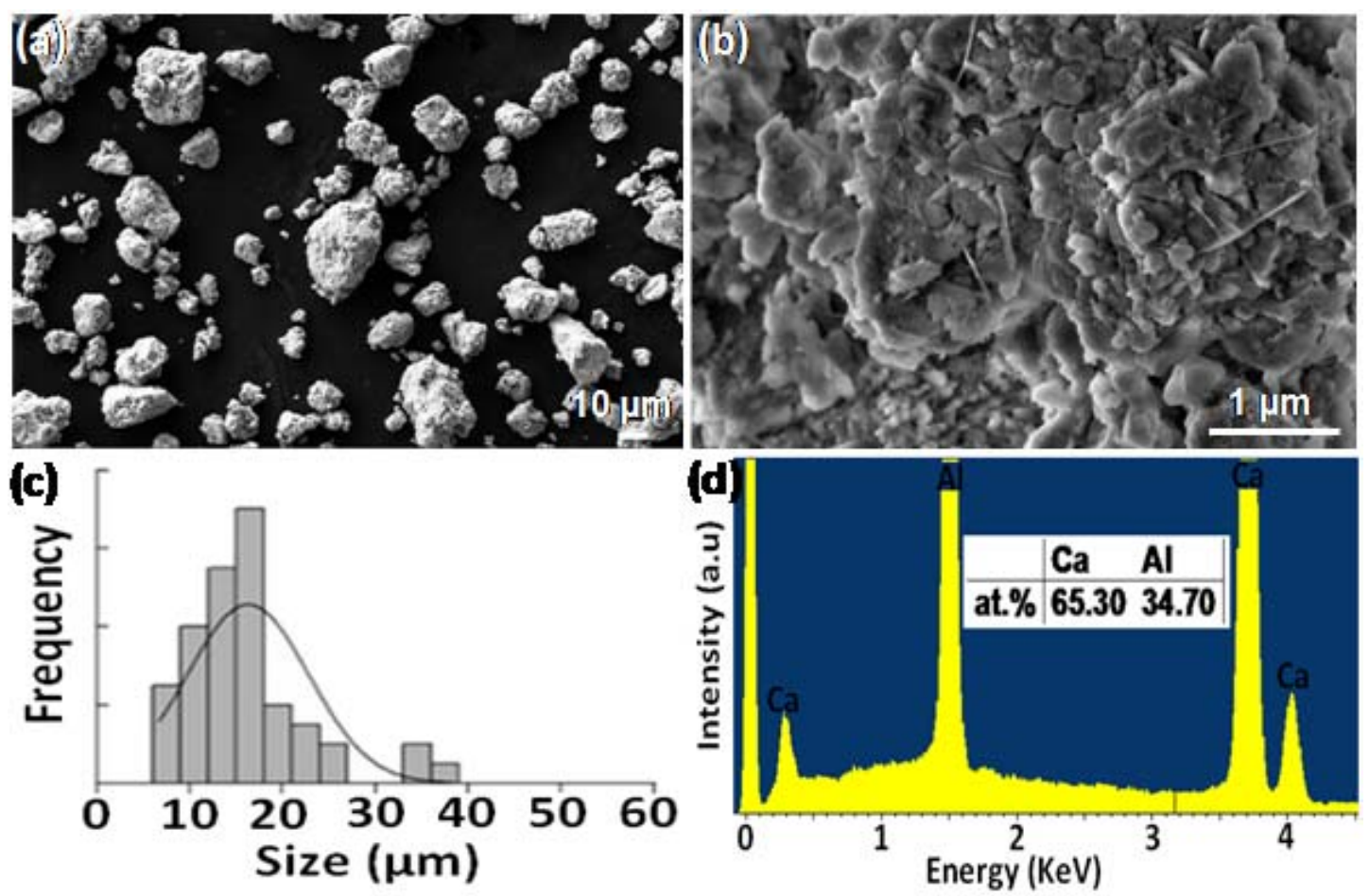

Figure 1. $(\mathrm{a}, \mathrm{b})$ Particles morphology of the $\mathrm{Ca}_{65} \mathrm{Al}_{35}$ particles before the decolorization process. (c) Distribution of particle sizes of the ball milled powders. (d) Chemical composition as examined by EDX. 

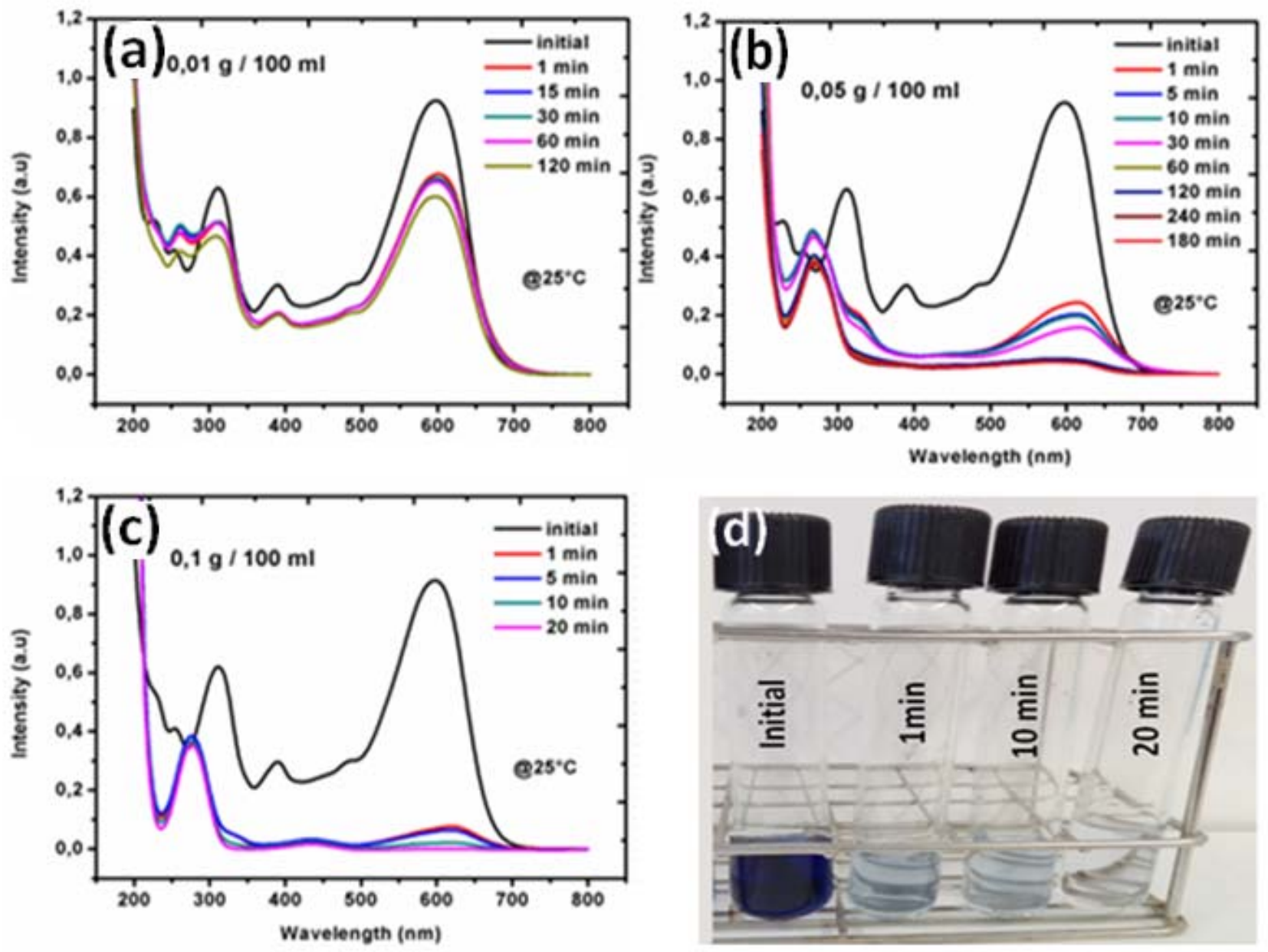

Figure 2.(a-c) The changes of UV absorption spectra along the treatment with $\mathrm{Ca}_{65} \mathrm{Al}_{35}$ particles at $25^{\circ} \mathrm{C}$ for different dosages of powder. (d) Image of Reactive Black 5 solutions processed by $\mathrm{Ca}_{65} \mathrm{Al}_{35}$ powder before and after degradation times up to $20 \mathrm{~min}$. 


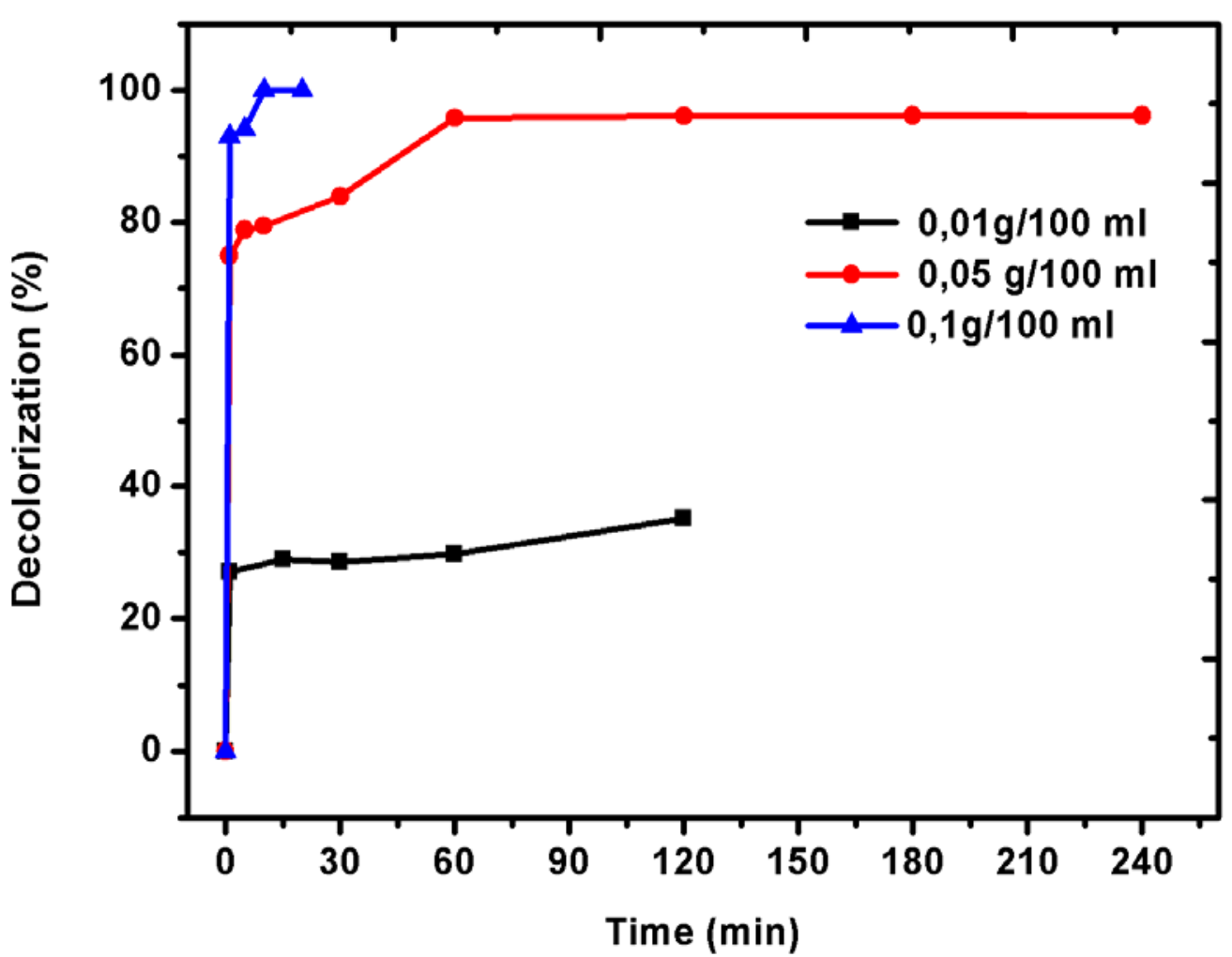

Figure 3. Kinetics of decolorization of RB5 dyed water using different particleweight/solution-volume ratios of $\mathrm{BM} \mathrm{Ca}_{65} \mathrm{Al}_{35}$ powder: $0.01 \mathrm{~g} / 100 \mathrm{~mL}, 0.05 \mathrm{~g} / \mathrm{mL}$ and $0.1 \mathrm{~g} / 100 \mathrm{~mL}$ of particles in $40 \mathrm{mg} \mathrm{L}^{-1} \mathrm{RB} 5$ aqueous solution. 

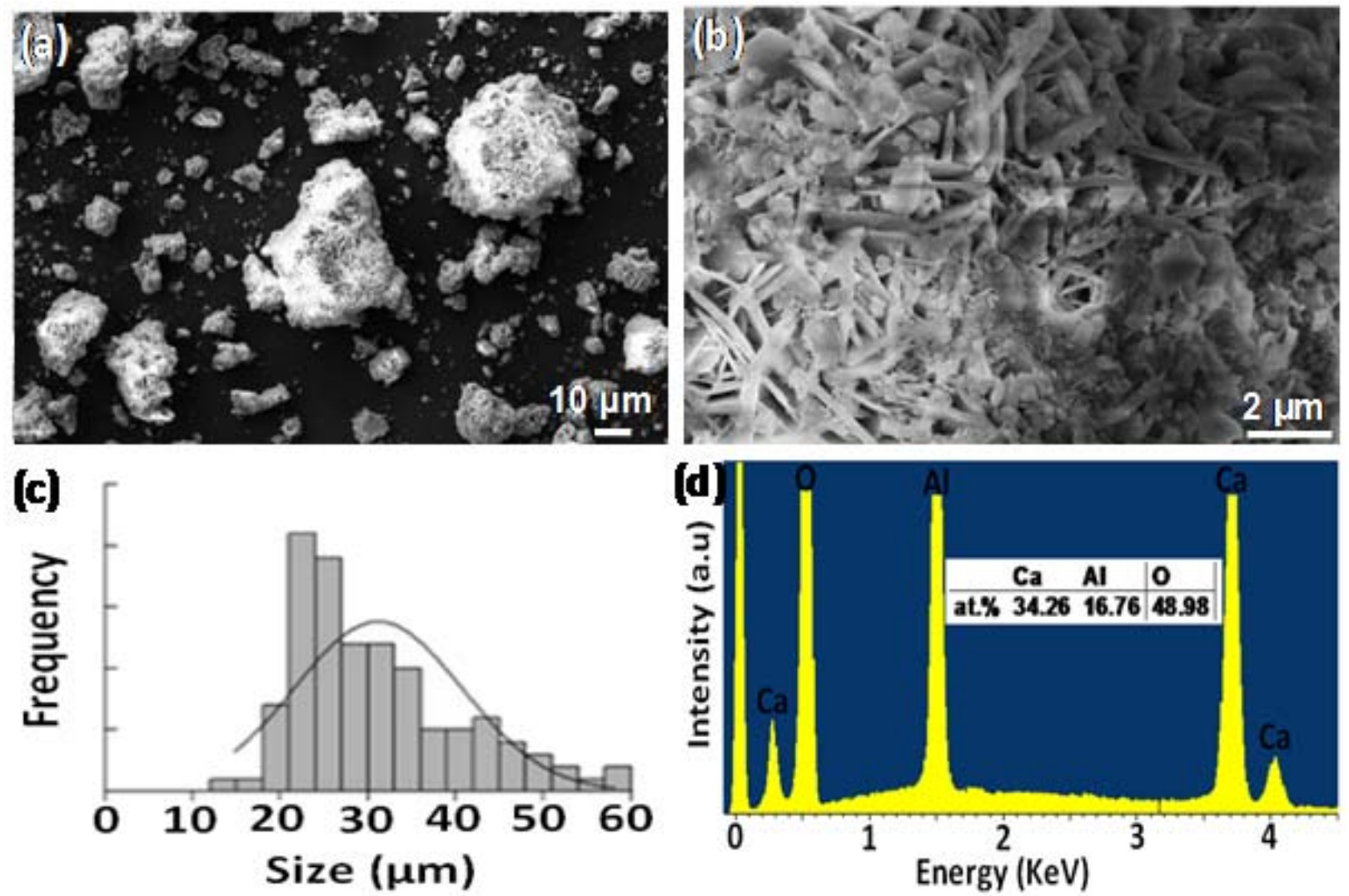

Figure4. $(\mathrm{a}$ and $\mathrm{b})$ Particle morphologies of the of $\mathrm{Ca}_{65} \mathrm{Al}_{35}$ powder after the decolorization process. (c) Distribution of particle sizes of the ball milled powders. (d) The chemical composition as examined by EDX. 


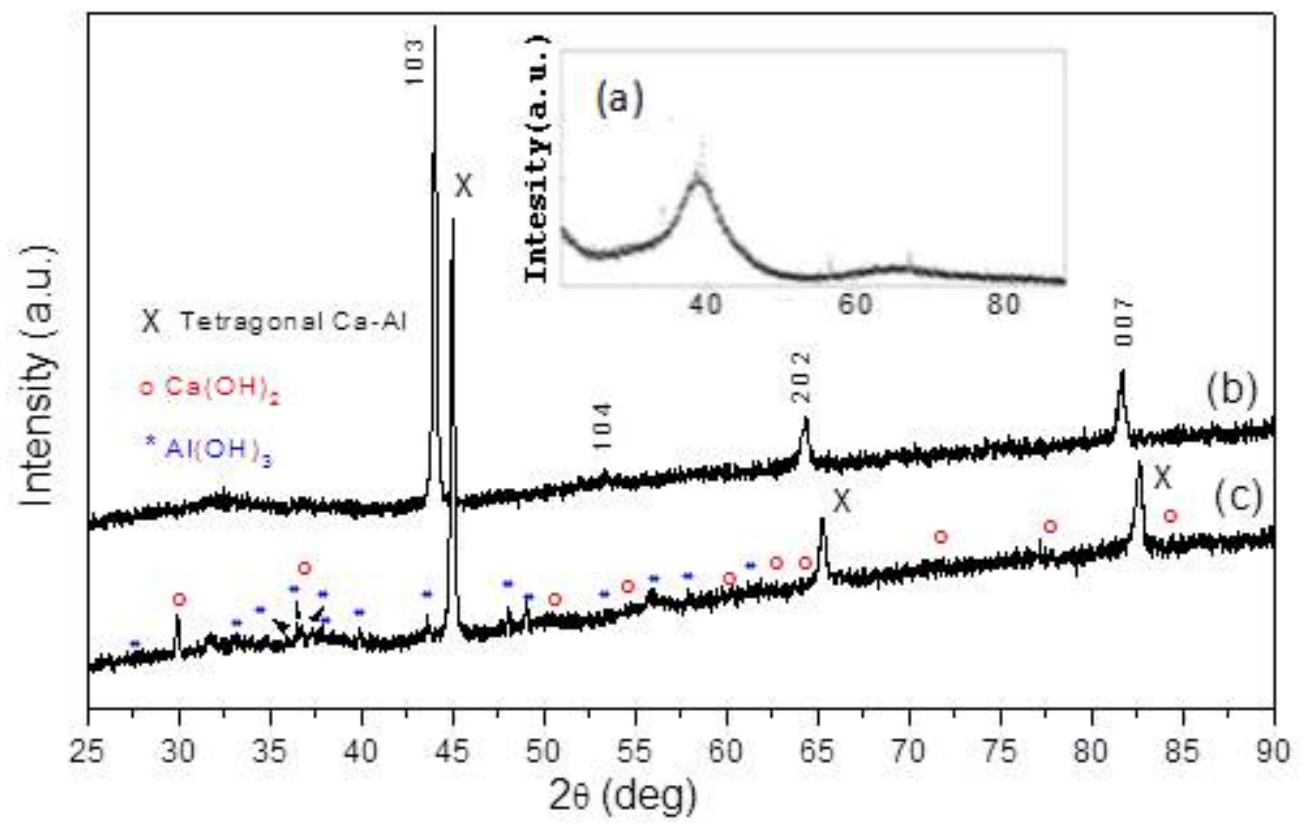

Figure 5. (a) The XRD patterns of the $\mathrm{Ca}_{65} \mathrm{Al}_{35}$ melt-spun ribbon. The Rietveld refinements of XRD patterns of the ribbon milled before (b) and after (c) the degradation of Reactive Black 5 . 


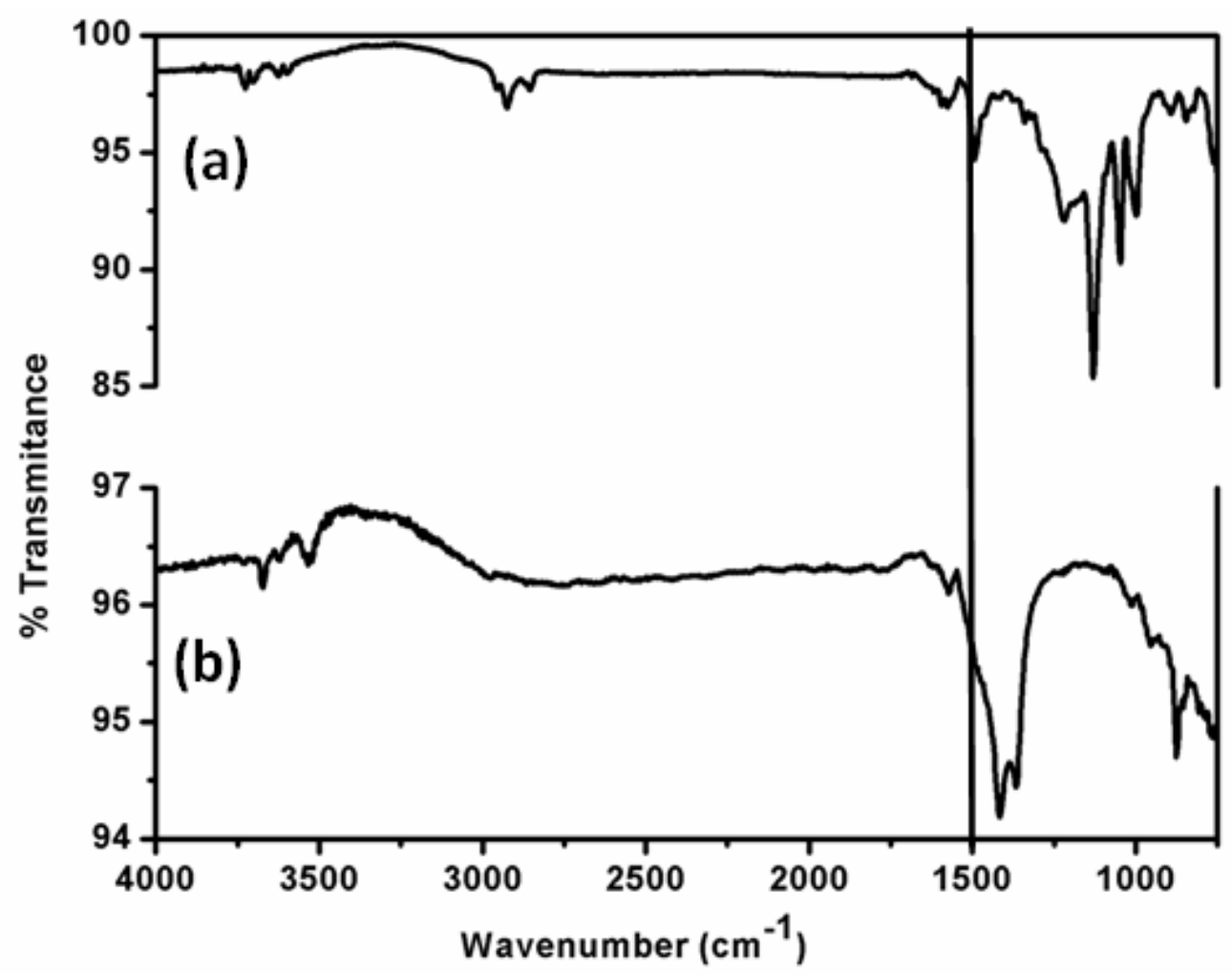

Figure 6. (a) FTIR spectra of RB5 powder before degradation reaction and (b) FTIR spectra of $\mathrm{Ca}_{65} \mathrm{Al}_{35}$ powder after degradation of reactive black 5 . 


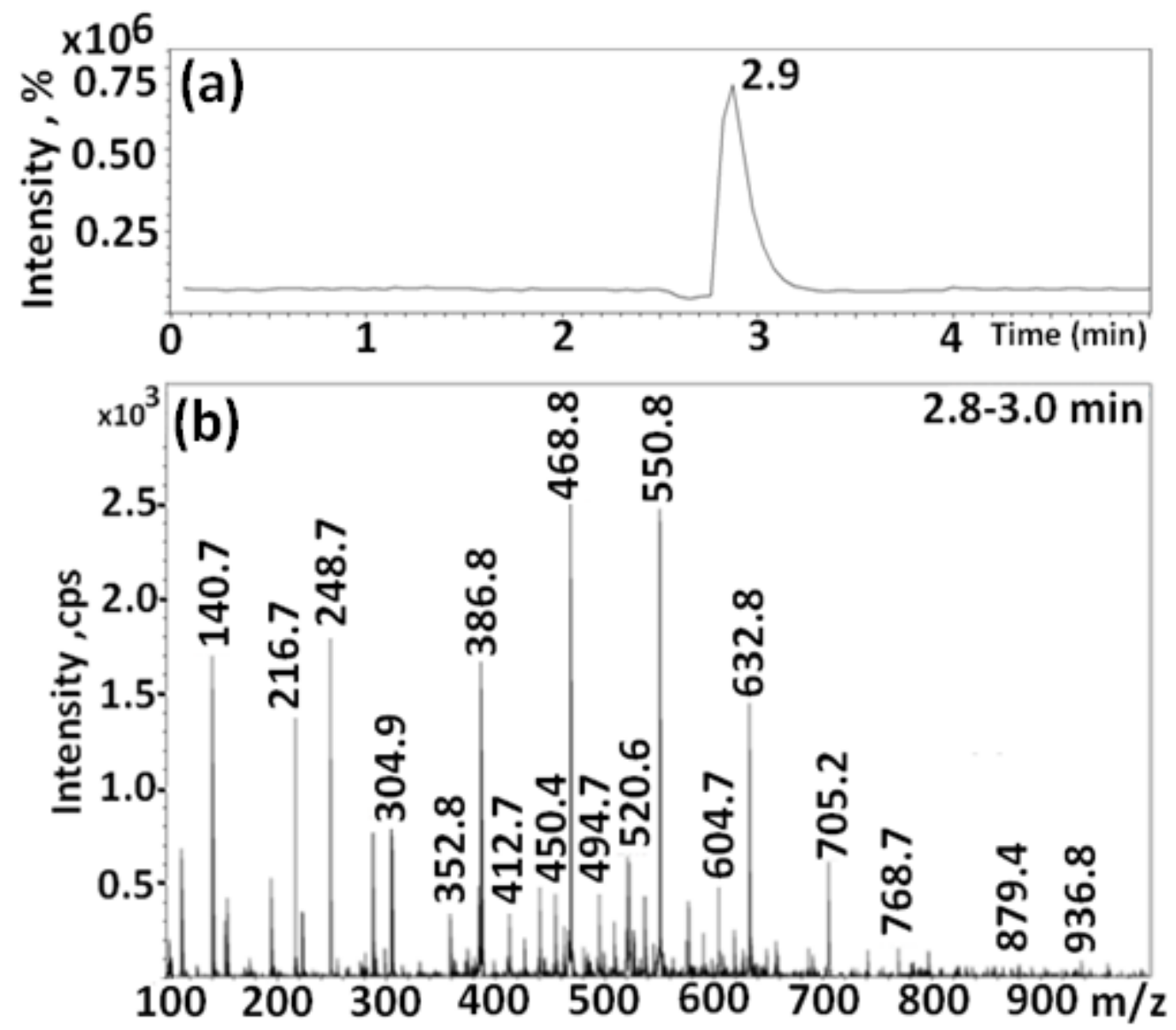

Figure 7. HPLC elution profile of the native black 5 dye and mass spectrums of the peak from (a) 2.9 min at (b) $\lambda=597 \mathrm{~nm}$. 

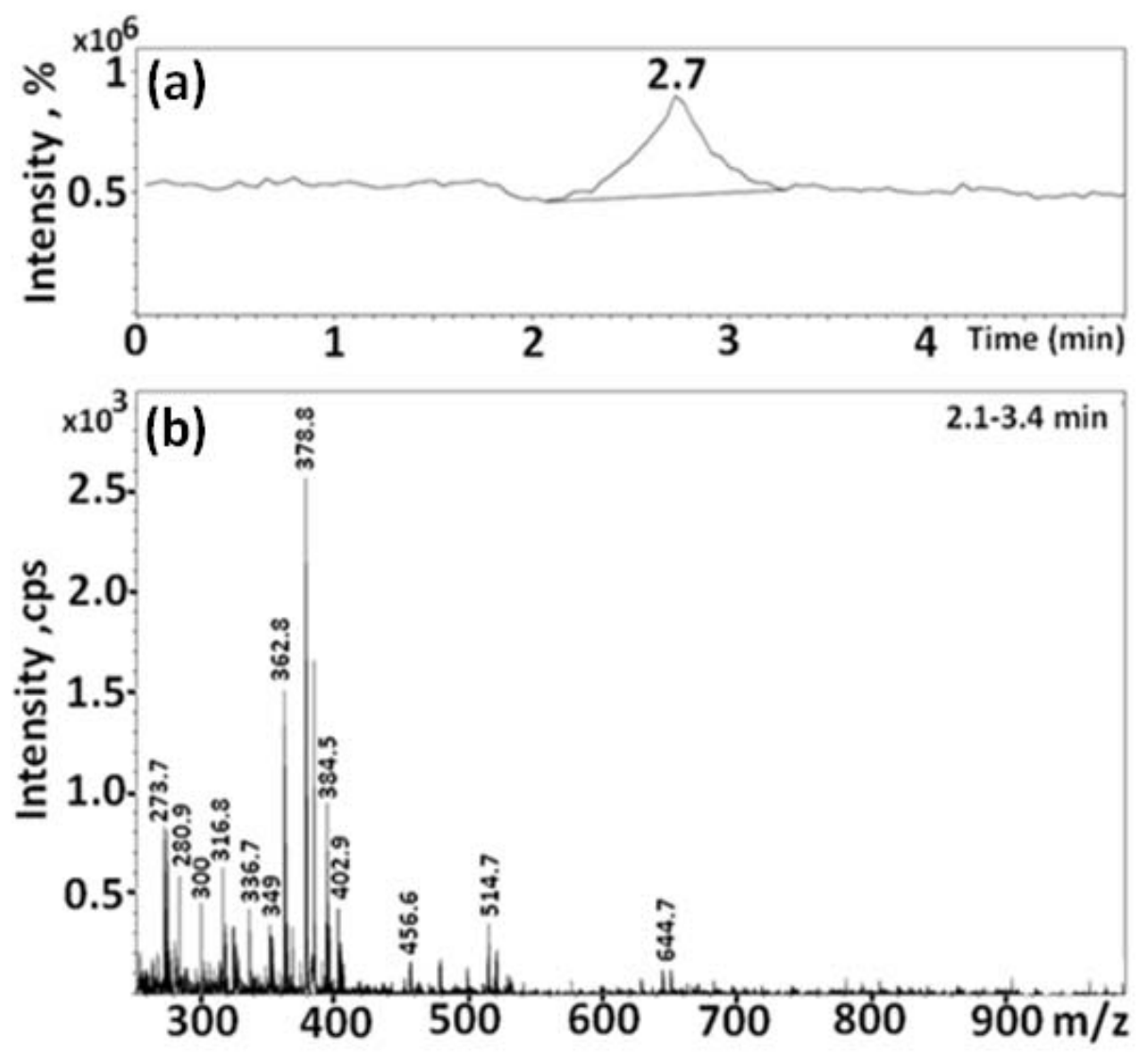

Figure 8. (a) HPLC elution profiles after degradation of the RB5 dye and (b) mass spectrua of peaks from $2.7 \mathrm{~min}$. 


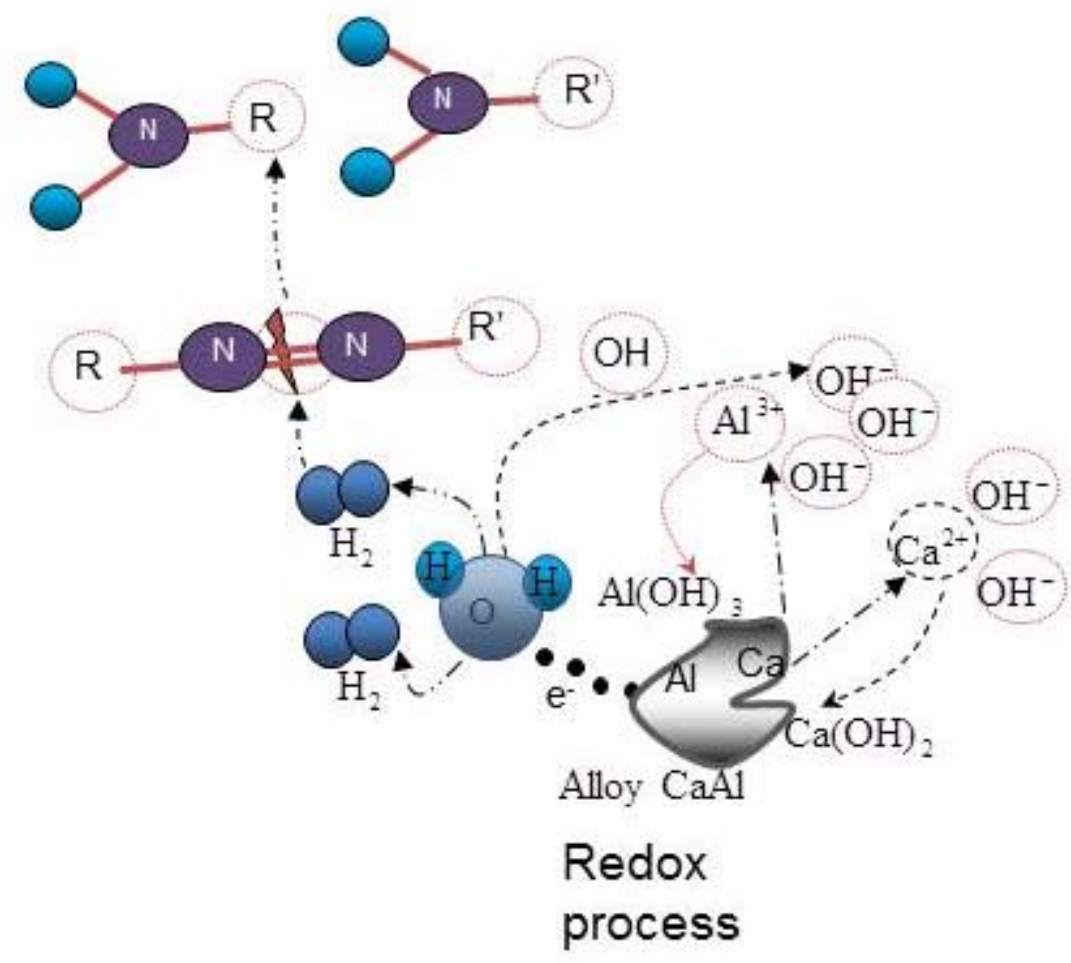

Figure 9. A schematic view of the proposed degradation mechanism of RB5 using $\mathrm{Ca}_{65} \mathrm{Al}_{35}$ compound. 